\title{
ARTIKULASI IDENTITAS LOKAL CEPU DALAM NOVEL PENANGSANG: TEMBANG RINDU DENDAM KARYA NASSIRUN PURWOKARTUN (TINJAUAN NEW HISTORICISM)
}

\author{
Sukarjo Waluyo \\ Departemen Sastra, Fakultas Ilmu Budaya, Universitas Diponegoro \\ sukarjowaluyo@gmail.com
}

(Naskah Diterima tanggal 17 Januari 2020_-Direvisi tanggal 28 Maret 2020_Disetujui tanggal 29 Maret 2020)

\begin{abstract}
Literature of a cultural product always interacts with social problems, including issues of locality and local identity. The problem of local identity in the novel Penangsang: Tembang Rindu Dendam is the main concern in this study. The background of the local locality and identity of Cepu which became the center of the Duchy of Jipang in the past was the setting of a place, as well as a space where the final historical and cultural journey of the power of the Demak Sultanate took place. This novel was written in 2010 by Nassirun Purwokartun. This historical novel invites us to rethink Cepu's locality and local identity, which has been a legacy of past generations. Articulation of identity and locality issues seem to be the attention voiced in this novel as well as being an instrument or instrument of articulation. This study uses the New Historicism approach, one literary theory that views history, art, and other things in society has the same degree as the text data in literature. It is hoped that literary research will get the context of the problem in accordance with the situation of the community.
\end{abstract}

Keywords: Cepu, articulation, local identity, New Historicism

\section{PENDAHULUAN}

permasalahan yang mendapat banyak perhatian pascareformasi 1998. Bagi pemerintahan kabupaten dan kota, hal ini seharusnya dimaknai sebagai kesempatan untuk melakukan improvisasi. Tokoh Arya Penangsang bagi Cepu pada dasarnya adalah sebuah gagasan budaya (dengan simbol, mitos, dan upacaranya) untuk membayangkan suatu peristiwa yang sebenarnya tidak terjadi pada masa kini. Dengan tokoh lokal tersebut, masyarakat menjadikan sesuatu yang dibayangkan bersama itu hadir. Anderson (1983) mengungkapkan tentang imajined community (komunitas terbayangkan), para warga komunitas meskipun tidak saling kenal, tidak pernah saling jumpa, tidak pernah saling berkirim kabar, tetapi mereka merasa saling terikat, (seakan-akan) mempunyai keprihatinan yang sama terhadap peristiwa dan informasi yang
Lokalitas dan identitas lokal di Indonesia menjadi

disajikan. Dari masing-masing pikiran anggotanya ada kesatuan persaudaraan horisontal yang bahkan membuat para warganya memiliki perasaan senasib dan rela mati demi kepentingan imajinatif tersebut.

Sosok Arya Penangsang yang menjadi tokoh utama dalam novel Penangsang: Tembang Rindu Dendam menjadi sesuatu yang penting dalam penelitian ini karena masyarakat Cepu memiliki pandangan sendiri tentang sosok tokoh penguasa Jipang tersebut sebagai pemimpin kharismatik mereka yang sangat dihormati. Salah satu bagian dari Babad Tanah Djawi mengisahkan tentang sosok penguasa Jipang yang bernama Arya Penangsang atau Arya Jipang (Adipati Jipang yang memerintah pada pertengahan abad ke-16). Tragedi sejarah pasca terbunuhnya Sultan Demak IV (Sunan 
Prawata atau Sultan Mukmin) ikut mengusik sosoknya. Pembunuhan dialamatkan kepadanya sebagai balas dendam atas pembunuhan ayahnya untuk memuluskan langkah Raden Trenggana (ayah Pangeran Prawata) menjadi Sultan Demak III saat terjadi suksesi kepemimpinan setelah meninggalnya Pati Unus (Sultan Demak II) yang tidak memiliki putra. Pangeran Sekar dan Raden Trenggana sebagai sesama putra Raden Patah berebut tahta Demak untuk menggantikan Pati Unus (Olthof, 2014:6274).

Kekalahan Arya Penangsang dari Hadiwijaya (Adipati Pajang dan menantu Sunan Prawata) dalam suksesi kepemimpinan Demak yang syarat dengan intrik dan berbagai kepentingan yang saling beradu membuatnya menjadi sosok yang dihakimi. Wacana buruk tentang sosoknya sengaja dibangun oleh kekuasaan Sultan Hadiwijaya dan Kesultanan Pajang sebagai pemenang. Hal ini kemudian dilanjutkan oleh Kesultanan Mataram dan Kraton Surakarta untuk kepentingan hegemoni dan kekuasaan.

Di balik sosoknya yang sentral bagi masyarakat $\mathrm{Cepu}$, ada banyak hal lain yang menyertainya yang mampu membangun memori kolektif mereka. Seperti kuda kesayangan Gagak Rimang yang dijadikan ikon kota, makam tua kadipaten Astana Gedong Ageng, Astana Santri Pitu, bekas areal kadipaten yang terjaga meski berubah menjadi persawahan, ataupun Bengawan Sore yang menjadi tempat pertempuran Penangsang melawan Danang Sutawijaya (Danang Sutawijaya adalah anak angkat Hadiwijaya yang kelak menjadi Raja Mataram I yang dikenal dengan Panembahan Senopati).

Pengakuan atas kepahlawanan Arya Penangsang bagi masyarakat Cepu akan berarti pemberian otoritas. Semakin kuat identitas dan eksistensi suatu komunitas maka akan semakin meningkat otoritas komunitas tersebut. Otoritas ini tidak hanya terbatas pada kehidupan dan eksistensi kepahlawanan tokoh lokal tersebut, tetapi berpengaruh luas dalam aspek-aspek kehidupan lainnya, seperti ekonomi, sosial, dan politik. Sosok heroisme Arya Penangsang pada saat ini juga dimaknai sebagai semangat untuk menentang ketidakadilan. Representasi identitas dan isu lokalitas di sekitar Cepu yang sangat keras juga diilhami bagaimana masyarakat memaknai lingkungan sosial sebagai ikatan sejarah dan budaya.

Paparan di atas menjelaskan bahwa masalah utama yang dikaji dalam penelitian ini adalah bahwa novel PTRD berusaha membangun konstruksi dan artikulasi identitas lokal masyarakat Cepu. Keberadaan tokoh utama (Arya Penangsang) tersebut telah berlangsung lama harus berkontestasi wacana penguasa (sejak kekuasaan Pajang, Mataram, Surakarta, hingga Indonesia merdeka) yang menjadi wacana dominan bagi masyarakat Jawa pada umumnya. Kisah Arya Penangsang yang disertai simbol-simbol, mitos, dan kisah heroisme mantan Adipati Jipang yang masih terjaga tersebut pada akhirnya menjadi memori kolektif mereka untuk membangun sebuah komunitas terbayangkan (imajined community). Penelitian ini selanjutkan akan menjelaskan terbangunnya konstruksi dan artikulasi identitas lokal masyarakat Cepu yang khas sebagai representasi identitas dan strategi untuk melakukan resistensi terhadap wacana dominan. Data-data dalam penelitian ini adalah teks-teks yang tertuang dalam naskah novel PTRD. Selanjutnya teks-teks dan keterangan di luar karya sastra juga menggambarkan kondisi dan isu menjadi pendukung.

Artikulasi, kesejarahan, memori kolektif, dan identitas, merupakan konsepkonsep yang digunakan dalam penelitian ini. Konsep-konsep tersebut dapat dijelaskan sendiri-sendiri, tetapi penelitian ini melihatnya sebagai hubungan yang bersifat saling menjelaskan. Kesejarahan dan memori kolektif dapat menjadi medium 
untuk melihat bagaimana konstruksi dan artikulasi identitas lokal Cepu.

Stuart Hall mendefinisikan artikulasi sebagai berikut.

"By the term, "articulation," I mean a connection or link which is not necessarily given in all cases, as a law or a fact of life, but which requires particular conditions of existence to appear at all, which has to be positively sustained by specific processes, which is not "eternal" but has constantly to be renewed, which can under some circumstances disappear or be overthrown, leading to the old linkages being dissolved and new connectionsre-articulation-being forged. It is also important that an articulation between different practices does not mean that they become identical or that the one is dissolved into the other. Each retains is distinct determinations and conditions of existence. However, once an articulation is made, the two practices can function together, not as an "immediate identity" (in the laguage of Marx's "1857 Introduction") but as "distinctions within a unity” (Hall, 1985:113-114).

Dalam konteks circuit of culture, teori artikulasi menyatakan tentang koneksitas antara dua atau lebih elemen circuit of culture yang berbeda dalam pembentukan makna (meaning) sebuah produk budaya selalu terjadi pada sebuah kondisi tertentu (under certain conditions). Teori ini menjelaskan bahwa produksi makna (production of meaning) tidak terjadi hanya pada salah satu elemen (misalnya: produksi), melainkan dari kombinasi proses antarelemen dalam circuit of culture, yaitu produksi (production), konsumsi (consumption), regulasi (regulation), representasi (representation), dan identitas (identity). Semua proses yang sangat kompleks tersebut terjadi dalam kondisi dan bentuk masing-masing yang berbeda antara yang satu dengan yang lainnya. Artinya, proses tersebut tidak mempunyai pola yang pasti/tetap.
Kesejarahan atau kesadaran sejarah merupakan pembentuk imajinasi mental dari tindakan yang akan diambil oleh seseorang. Selain itu, kesejarahan melalui ingatan kolektif dapat menjadi pembentuk identitas, seperti identitas etnis, agama, keadaran ras, dan golongan tertentu. Kesejarahan dapat dibedakan secara konseptual dengan sejarah. Kesejarahan bukanlah berasal dari rangkaian peristiwa yang bersifat kronologis, melainkan bisa saja dua atau tiga kejadian yang secara sejarah berkaitan walaupun dalam tahuntahun yang berbeda. Hal ini berbeda dengan pendekatan sejarah yang merupakan deskripsi linier tentang peristiwa yang dipahami dalam sebuah skema yang kronologis (Arnet, 2002:503).

Memori kolektif dalam perspektif Halbswach adalah sebuah rekonstruksi tentang masa lalu dalam nuansa kekinian (1992:34). Konstruksi pemikiran versi Halbswach ini menegasikan tentang pentingnya peran individual dalam membentuk suatu memori kolektif. Bagi Kansteiner, memori kolektif bukanlah sejarah, walaupun terkadang mengambil dari material yang sama. Ia merupakan fenomena kolektif, tetapi hanya tampak dalam tindakan dan pernyataan dari individu (2002:180). Memori kolektif merupakan kumulatif dari narasi-narasi personal, kemudian narasi personal yang mempunyai kesamaan itulah yang ditransmisikan menjadi memori kolektif.

Kesejarahan dan identitas adalah dua konsep yang saling memengaruhi. Tesis memory is shaping identity dapat ditemukan pada berbagai kasus-kasus kekerasan yang bernuansa etnis, agama, dan golongangolongan tertentu. Ingatan-ingatan tentang peristiwa yang traumatis biasanya menebalkan perasaan sebagai bagian atau di luar bagian dari suatu kelompok, karena identitas pada dasarnya membicarakan tentang perasaan seseorang tentang dirinya dalam hubungannya dengan orang lain dan masyarakat umum (Benda Beckman dalam Ramstedt dan Thufail, 2010). 
Identitas itu bersifat majemuk, dan bahwa taraf kepentingan suatu identitas tidak harus meniadakan kepentingan identitas lainnya (Sen, 2007:27). Pernyataan tersebut bisa menjadi argumentasi bahwa konteks sosial adalah sesuatu hal yang tampaknya menjadi penting dalam pemilihan konstruksi dan membangun identitas suatu kelompok atau masyarakat. Alasan kesejarahan dan perasaan senasib seperjuangan bisa menjadi pilihan penanda identitas suatu kelompok atau masyarakat.

Berdasarkan paparan pada latar belakang tersebut, masalah pokok yang dikembangkan dalam penelitian artikel ini adalah bagaimana artikulasi identitas lokal Cepu dalam novel PTRD dengan tinjauan New Historicism. Masalah pokok tersebut kemudian diturunkan ke dalam beberapa pertanyaan yaitu bagaimanakah artikulasi identitas lokal Cepu dalam novel PTRD dan mengapa masyarakat Cepu bersemangat mengartikulasikan identitas lokalnya.

\section{METODE}

Penelitian ini menggunakan pendekatan ini new historicism (NH) yang mengaitkan antara teks sastra dengan nonsastra. Istilah NH pertama kali digunakan oleh Stephen Greenblatt pada tahun 1982 yang mencoba melihat keterkaitan teks sastra dengan berbagai kekuatan sosial, ekonomi, dan politik yang melingkupinya. Budianta (2006) dalam Jurnal Susastra melihat bahwa $\mathrm{NH}$ tidak dapat dilepaskan dari teoriteori post-strukturalis seperti teori Dekonstruksi Jaques Derrida atau keterikatan antara tanda dan ideologi yang diungkapkan oleh Roland Barthes. NH banyak bertumpu pada konsep kekuasaan Michel Foucault yaitu keniscayaan yang selalu hadir dalam setiap interaksi manusia, termasuk bahasa. Karena relasi kuasa bersirkulasi terus-menerus tanpa henti mendorong kreativitas dan produktivitas, karya sastra dengan sendirinya menghadirkan relasi kuasa itu melalui bahasa yang dipakainya. Pengaruh Clifford Geertz tampak pada metode "thick description" yaitu metode etnografi untuk memahami suatu produk budaya lain dengan rinci mengupas lapisan makna yang kompleks dalam kode-kode budaya yang mendasarinya.

NH juga menunjukkan kekayaan kekayaan yang ditawarkan oleh studi lintas disiplin, antara sejarah, sastra, ekonomi, dan politik. Teks novel PTRD dalam penelitian ini pada dasarnya bukanlah teks yang berdiri sendiri. Keterkaitannya dengan teks-teks lain, cerita lisan, tempat bersejarah, legenda, monumen, lingkungan, dan kesenian menjadikan pendekatan $\mathrm{NH}$ sangat relevan. Sementara itu, metode kepustakaan dengan membaca dekat dan pencatatan data-data yang penting dilakukan dalam penelitian ini.

\section{PEMBAHASAN \\ Sejarah Kebesaran Kesultanan Demak sebagai Latar}

Tokoh Arya Penangsang adalah tokoh utama dalam novel PTRD. Pengarang memulai menuliskan kisahnya dengan menarik ke dalam masalah suksesi Kesultanan Demak. Hal ini membuat novel PTRD memberikan ruang yang lebih luas dalam membicarakan tokoh utama dan menghindari stigma yang sudah terlanjur secara berseberangan antara Jawa Mataraman di satu sisi dengan masyarakat Cepu di sisi yang lain. Dalam tetralogi novel yang pertama, PTRD, permulaan cerita dibuka dengan penggambaran kondisi Kesultanan Demak pada sekitar abad ke-16.

Kesultanan Demak dilukiskan sebagai kerajaan Islam terbesar di tanah Jawa pasca kehancuran Kerajaan Majapahit. Sebagai penerus Majapahit (Raden Patah adalah putra Brawijaya dengan putri Cina), Demak adalah kerajaan Islam yang dilukiskan membawa zaman baru dan pencerahan bagi tanah Jawa. Islam digambarkan sebagai ajaran keselamatan dan perdamaian yang 
menjadi dasar Kesultanan Demak yang didirikan para ulama untuk mewujudkannya dalam pemerintahan nyata. Perdamaian di tanah Jawa dipertahankan dengan mengajak bergabung kerajaan-kerajaan kecil sisa-sisa kejayaan Majapahit bersatu padu dalam panji lintang rembulan untuk menjaga ketenteraman bersama. Ada yang bergabung kemudian ikut masuk dalam ajaran agama Islam, ada juga yang tetap merdeka dengan keyakinannya yang lama. Bagi yang tidak mau bergabung, tetapi tidak melakukan permusuhan, tetap dihormati keberadaannya. Sementara, yang tetap menentang, bahkan mengadakan pemberontakan, Kesultanan Demak memberikan perlawanan. Ini terlihat dalam kutipan berikut.

\section{Abad keenam belas Masehi.}

Tanah Jawa yang gulita tengah diterangi cahaya baru.

Ngadiyati puniku.

"Itulah hati yang indah," demikian seorang pujangga menorehkannya dalam sebuah babad.

"Ketika itu, di Tanah Jawa telah masuk Islam semua, tiada lagi yang menentang. Para pertapa, begawan dan pembantunya, pengikut dan muridnya, banyak yang telah menerima keimanan. Dan, brahmana beserta para resinya telah berganti dengan ahli-ahli fikih ternama. Para pendeta berganti dengan ulama-ulama luhur, para zahid dan mu'ahid, mufti dan sulakha, para hukuma yang hebat.

Kesultanan Demak berdiri tegak. Dan, terus berkembang menyebarkan ajaran Islam ke seluruh tanah Jawa.

Selama 40 tahun Raden Patah berkuasa, telah mampu membawa Demak menjadi kerajaan terbesar di tanah Jawa. Sejajar dengan Kesultanan Malaka di Semenanjung Malaya dan Kesultanan Pasai di ujung utara Pulau Samudera (PTRD, 2010:3-4).

Sebagai sebuah kerajaan besar, Kesultanan Demak senantiasa memiliki kewaspadaan dari segala ancaman, baik dari dalam maupun luar. Ancaman dari dalam adalah wilayah dari bekas Kerajaan Majapahit yang tidak mau mengakui Demak, sedangkan dari luar berkaitan dengan kedatangan bangsa Portugis dan Spanyol yang sudah mulai menginjakkan kaki di Semenanjung Malaka.

\section{Kekalahan Kadipaten Jipang dalam Suksesi Kesultanan Demak}

Di tengah ancaman yang menghadang, Kesultanan Demak justru dihadapkan pada masalah suksesi yang tidak berjalan dengan mulus. Raden Patah sebagai pendiri dan Sultan I Demak naik tahta pada umur 23 tahun memerintah selama 40 tahun (14781518 M). Setelah meninggal (usia 63 tahun), anaknya yang bernama Pati Unus naik tahta pada usia 18 tahun dan memerintah selama 3 tahun (1518-1521 M) karena meninggal pada usia muda dan belum memiliki putra. Naiknya Pati Unus (menjadi Sultan II) diterima oleh keluarga Kesultanan karena Pati Unus dianggap berjasa ketika mampu memajukan Jepara ketika menjabat sebagai adipati dan berjasa dalam penyerangan terhadap Portugis di Malaka sehingga dikenal juga sebagai Pangeran Sabrang Lor. Kematian Pati Unus yang belum memiliki putra inilah yang membuat kedua saudaranya, yaitu Pangeran Sekar dan Raden Trenggana (adiknya) berebut tahta yang berakhir dengan terbunuhnya Pangeran Sekar oleh anak Raden Trenggana yang bernama Pangeran Prawata.

Raden Trenggana akhirnya naik tahta menjadi Sultan Demak III dan memerintah selama 25 tahun (1521-1546). Di bawah kekuasaannya, ketenteraman perdamaian tanah Jawa makin dimantapkan. Kesultanan Demak pun merasa aman terhadap ancaman dari dalam, dengan tunduknya hampir seluruh wilayah pesisir utara tanah Jawa. Namun, Sultan Trenggana terbunuh di Panarukan saat turut serta dalam penyerangan ke bagian timur tanah Jawa. Kematian Sultan Trenggana itulah yang membuat dendam dan perebutan tahta 
antarkeluarga Kesultanan Demak terulang kembali. Ini terlihat dalam kutipan berikut.

Namun, dengan wafatnya Trenggono, Kesultanan Demak Bintoro terguncang.

Keguncangan yang bermula dari dendam lama. Kematian Pati Unus yang belum mempunyai anak, meninggalkan pertikaian pada para penerusnya. Terjadi perebutan takhta antarsaudara, antara Pangeran Sekar dan Raden Trenggono. Dalam pertikaian antaranak Raden Patah itu, Pangeran Sekar terbunuh.

Dan, dengan wafatnya Trenggono, anak Pangeran Sekar yang bernama Haryo Penangsang berniat menuntut hak atas ayahnya (PTRD, 2010:5).

Novel PTRD mengungkapkan juga adanya sosok lain yang turut serta dalam pertikaian tersebut. Sosok ini tidak disebutkan pada bagian awal dengan jelas, tetapi muncul sebagai tokoh yang sangat kuat dalam pergulatan politik memperebutkan tahta Demak sepeninggal Sultan Trenggana dan Sultan Prawata, yaitu Jaka Tingkir yang setelah menjadi menantu Sultan Trenggana lebih dikenal sebagai Hadiwijaya yang berkuasa sebagai Adipati Pajang. Ini terlihat dalam kutipan berikut.

Bara kesumat mulai berkobar membakar Takhta Demak.

Karena dibalik kemelut tersebut, ada sosok yang juga menyimpan dendam lama. Dan, tengah rindu untuk segera melampiaskan dengan merebut kekuasaan Kesultanan.

Peristiwa perebutan takhta kembali berulang dengan tegang.

Tembang rindu dendam pun lamatlamat berkumandang.

Keni kinarya darsana, panglimbang ala lan becik, Sayakti akeh kewala, lalakon kang dadi tamsil, Masalahing ngaurip.... Cerita ini dapat dipakai teladan, Untuk menimbang keburukan dan kebaikan, tentulah banyak sudah,

\section{Lelakon yang menjadi contoh, dalam kehidupan.... \\ (PTRD, 2010:5-6).}

Novel PTRD juga mengulas seputar perebutan tahta antara Pengeran Sekar dengan Raden Trenggana secara flashback (sorot balik) melalui tokoh Patih Mataun dan Sunan Kudus yang banyak menceritakan kisah masa lalu Pangeran Sekar dalam dialog dengan dirinya sendiri maupun dalam perbincangan dengan Arya Penangsang. Novel PTRD ingin memberikan gambaran bahwa tindakan balas dendam atas kematian ayahnya dan upaya merebut kembali tahta yang seharusnya jatuh ke tangan ayahnya adalah hal yang tidak sepenuhnya keliru. Perseteruan antarkeluarga Kesultanan Demak justru menjadi tajam saat munculnya tokoh dari pihak luar yang mengakibatkan kejatuhan keluarga Kesultanan dan berakibat munculnya dinasti baru di tanah Jawa yang melenceng, yaitu Hadiwijaya yang memindahkan pemerintahan kesultanan dari Demak ke Pajang.

Kepentingan mengonstruksi kekuasaan Pajang menjadi sangat penting bagi Hadiwijaya pasca terbunuhnya Adipati Arya Penangsang di Jipang. Hal ini karena Arya Penangsang adalah sosok yang dianggap sah (cucu Raden Patah) untuk mewarisi kekuasaan Kesultanan Demak saat terjadinya suksesi pasca terbunuhnya Sunan Prawata. Hal ini sangat beralasan, mengingat Hadiwijaya yang kelak menjadi Sultan di Pajang tidak memiliki trah (garis keturunan Sultan Demak). Ia adalah seorang Adipati di Pajang yang hanya menantu Sultan Trenggana. Dengan demikian, kematian Arya Penangsang telah menjadi klimaks dari perseteruan politik tentang siapa yang harus mewarisi tahta Kesultanan Demak.

\section{Arya Penangsang adalah Pangeran dan Pewaris Kesultanan Demak}


Sejauh mana upaya balas dendam Arya Penangsang memiliki dasar pembenaran, novel PTRD mencoba meletakkannya dalam konteks Demak yang merupakan Kesultanan Jawa Islam. Dalam konteks kekuasaan Jawa ada istilah urut kacang, yaitu urutan perolehan hak yang didapatkan berdasarkan hierarki (biasanya berdasarkan $n a s a b$ atau urutan keturunan). Sementara itu, hukum Islam mengenal istilah qishosh, yaitu diperbolehkannya membalas hukuman setimpal oleh ahli waris. Dua hal itulah yang membuat tetralogi novel Penangsang memberikan ruang yang lebih luas atas tokoh Arya Penangsang.

Istilah urut kacang memberikan ruang bahwa Pangeran Sekar (ayah Arya Penangsang) memiliki hak atas tahta Demak sepeninggal Pati Unus karena ia merupakan kakak dari Raden Trenggana. Saat terjadi perselisihan itulah anak Raden Trenggana (Pangeran Prawata) melakukan pembunuhan terhadap Pangeran Sekar setelah melaksanakan salat Jumat yang membuat Raden Trenggana bisa menduduki tahta Kesultanan Demak. Sementara itu dalam konteks hukum qishosh, Arya Penangsang memiliki dua pilihan antara memaafkan atau membalas dendam. Arya Penangsang digambarkan berada dalam posisi netral. Tindakan dan rencana balas dendam serta upaya meminta hak kembali ayahnya atas tahta Kesultanan Demak diwakili oleh sikap Patih Mataun. Ini terlihat dalam kutipan berikut.

\section{"Utang pati nyaur pati!"}

Lelaki tua itu mendongakkan pandang. Ia memandangi tombak panjang yang menancap di dahan tanjung yang rindang.

"Utang nyawa harus dibayar dengan nyawa," desisnya mengulang.

Ia terkenang kata-katanya yang telah memantik kemarahan Penangsang (PTRD, 2010:7).

Ia terkenang kata-kata yang telah membuat Penangsang meradang.

Ia kembali terkenang. Ada darah yang mengalir di Kali Tuntang.

"Prewosto telah berhutang
(PTRD, 2010:9).

'Prewosto' adalah sebutan kebencian Patih Mataun kepada Sunan Prawata yang dahulu telah membunuh Pangeran Sekar, ayah Penangsang. Patih Mataun sangat berharap agar Arya Penangsang merebut kembali hak ayahnya atas tahta Demak. Ia adalah saksi terbunuhnya Pangeran Sekar di tepi Kali Lusi dan menjadi orang tua angkat Arya Penangsang. Dikisahkan Patih Mataun adalah sosok patih tua yang sejak muda sudah mengabdikan diri dengan setia kepada Kadipaten Jipang sejak jabatan Adipati dipegang oleh Pangeran Sekar (ayah Arya Penangsang).

\section{Kadipaten Jipang sebagai Pembangun Ikatan Sejarah dan Memori Kolektif}

Kekuasaan Kadipaten Jipang adalah sebuah wilayah yang sangat luas meliputi Cepu, Blora, Pati, Rembang, Lasem, dan Bojonegoro. Salah satu putri kadipaten diperistri Raden Patah (Sultan Demak I) dan berputra Pangeran Sekar yang kemudian berkuasa di Jipang. Perebutan tahta Demak dengan adiknya, Raden Trenggana, membuatnya tewas terbunuh di Sungai di tangan Pangeran Prawata (anak Raden Trenggana). Kushariyadi (52) ${ }^{1}$, Ketua Yayasan Keraton Jipang, mengungkapkan bahwa Raden Kikin berputra Penangsang yang setelah remaja juga menuruni kekuasaan Jipang. Hal ini berulang setelah terbunuhnya Sultan Sultan Prawata (Sultan Demak IV dan anak Sultan Trenggana) yang ikut menyeret sosok Arya Penangsang. Kekalahannya dalam intrik politik dan perang melawan Hadiwijaya dari Pajang membuat sejarah hidupnya dituliskan dengan 'tinta hitam' oleh Kesultanan Pajang dan berlangsung hingga Kesultanan Mataram dan Kraton Surakarta.

\footnotetext{
${ }^{1}$ Wawancara dilakukan di rumah Kushariyadi (52) Desa Demaan, Padangan (Bojonegoro) tanggal 7 Januari 2018.
} 
Ahmad Zamroni (35) ${ }^{2}$ melihat upaya untuk mendiskreditkan Cepu sejak dari kekalahan Arya Penangsang yang jasadnya dimakamkan di Kadilangu (Demak) sebagai pertanda bahwa penguasa tidak ingin melihat Cepu sebagai daerah yang memiliki kekuatan politik, budaya, dan ekonomi. Dalam kasus PKI Madiun dan G 30 S/PKI 1965, Cepu dipersepsikan sebagai daerah pemberontak, padahal kondisi Cepu saat itu sama saja dengan daerah lain di sekitarnya. Ia juga mengungkapkan seakan ada upaya "Cepu adalah daerah kaya yang harus selalu dikalahkan." Sementara itu, dalam masyarakat Cepu juga muncul semacam kepercayaan bahwa orang Cepu akan sulit berkembang dan menjadi besar jika tidak merantau. "Keluarlah dari Cepu jika ingin jadi orang besar!" kata Zamroni menyebutkan adagium yang ada dalam masyarakat Cepu. Ia menyebut nama-nama, seperti Mas Marco Kartodikromo, Tirto Adhi Soerjo, Kartosuwiryo, Mukti Ali, LB Murdani, dan Pramudya Ananta Toer sebagai representasi orang Cepu dan Blora yang memiliki nama besar dalam panggung sejarah di Indonesia.

Dalam konteks ini, tokoh Arya Penangsang disebut sebagai imajined community (masyarakat terbayangkan) dari masyarakat Cepu sebagai bentuk resistensi dan mejadi wacana lokal/pinggiran. Jika di Solo dan Jogja Arya Penangsang (dan ayahnya) dianggap sebagai tokoh kontroversial yang mendapat stigma haus kekuasaan dan pemberontak, tidak demikian halnya dengan persepsi masyarakat Cepu. Mereka sangat menghormati kedua tokoh tersebut sebagai satria yang sangat tinggi. Mereka berdua dalam ungkapan Jawa disebut trahing satrio rembesing madu. Mereka berdua dianggap sebagai pangeran yang menuntut haknya.

\footnotetext{
${ }^{2}$ Wawancara dilakukan di rumah Zamroni (35) Desa Cendono, Padangan (Bojonegoro) tanggal 6 Januari 2018.
}

Dalam konteks masyarakat Cepu, sejarah Kadipaten Jipang bias dimaknai sebagai sumber pembangun ikatan sejarah dan memori kolektif, serta pembangun ikatan budaya dan komunitas terbayangkan (imagine community). Ikatan budaya masyarakat sekitar Cepu pada akhirnya bisa dikatakan sebagai subkultur budaya Jawa. Produksi budaya dalam beberapa bentuk, seperti bahasa, cerita lisan, pakaian, dan pandangan hidupnya menunjukkan hal yang khas yang berbeda dengan kebudayaan Jawa dominan (Solo dan Jogja). Mereka tidak sungkan dengan ungkapan nek iyo ya iyo, nek ora ya ora untuk mengungkapkan sikap apa adanya tanpa basa-basi. Juga ungkapan trah agawe congkrah untuk menafsirkan bahwa membicarakan leluhur yang berlebihan bisa membuat orang berebut untuk mendapatkan hak dan pengakuan. Akhirnya, kita harus menyadari bahwa masalah lingkungan sosial dan sejarah yang dimaknai oleh masyarakat Cepu sangat terkait dengan budaya dan identitas lokal. .

\section{PENUTUP}

Artikulasi dan konstruksi identitas lokal Cepu dalam yang tampak dalam novel PTRD memberikan perspektif baru. Karya sastra bisa memberikan perspektif yang bermanfaat sebagaimana analisis akademik dan ilmiah. Dalam identitas lokal Cepu, novel ini setidaknya memberikan empat pesan penting. Pertama, masyarakat memaknai lingkungan sosial selalu terkait dengan sejarah masa lalu mereka.

Kedua, sejarah masa lalu Kadipaten Jipang adalah pembangun ikatan sejarah dan memori kolektif masyarakat Cepu. Sosok Raden Kikin dan Arya Penangsang adalah sosok pahlawan lokal (local hero) yang mampu menyatukan mereka. Dalam konteks ini, tokoh Penangsang disebut sebagai imajined community (masyarakat terbayangkan) dari masyarakat yang berfungsi sebagai bentuk resistensi.

Ketiga, sejarah masa lalu Kadipaten Jipang adalah pembangun ikatan budaya 
dan imagine community. Ikatan budaya masyarakatnya pada akhirnya bisa dikatakan sebagai subkultur budaya Jawa. Produksi budaya dalam beberapa bentuk, seperti bahasa, cerita lisan, pakaian, dan

\section{DAFTAR PUSTAKA}

Anderson, Benedict. 2008.Imagined Communities (Komunitas-komunitas Terbayang) (terj.). Yogyakarta: Insist dan Pustaka Pelajar.

Arnet, Ronald C. 2002. "Paulo Freire's Revolutionary Pedagogy: From a Story-Centered to a NarrativeCentered Communication Ethics". Journal of Qualitative Inquiry 2002. Vol 8. Hal 489.

Budianta, Melani. 2006. "Budaya, Sejarah, dan Pasar: New Historicism dalam Perkembangan Kritik Sastra" dalam Jurnal Susastra, Vol. 2, No. 3 tahun 2006. Jakarta: Yayasan Obor.

Graaf, H.J. de. 1987. Awal Kebangkitan Mataram: Masa Pemerintahan Senapati (terj). Jakarta: Pustaka Grafitipers.

Halbwachs, Maurice. 1992. On Collective Memory. Chicago: University of Chicago Press.

Hall, Stuart. 1997. Representation: Cultural Representation and Signifying Practice. London: SAGE Publication Ltd.

Kansteiner, Wulf. 2002. "Finding Meaning in Memory: A Methodological pandangan hidupnya menunjukkan hal yang khas. Akhirnya, kita harus menyadari bahwa masalah identitas lokal yang dimaknai oleh masyarakat Cepu sangat terkait dengan kontertasi budaya.

Critique of Collective Memory Studies." Journal of History and Theory, Vol. 4 No. 2 (179-197).

Olthoff, W.L. 2014. Babad Tanah Jawi, Mulai dari Nabi Adam sampai Tahun 1647. (alih bahasa H.R. Sumarsono). Yogyakarta: Narasi.

Purwokartun, Nassirun. 2010. Penangsang (Tembang Rindu Dendam). Jakarta: Tiga Kelana.

Sen, Amartya. 2006. Kekerasan dan Ilusi tentang Identitas. Jakarta: Marjin Kiri.

\section{Sumber dari Internet}

Jipang, Cepu, Blora - Wikipedia bahasa Indonesia, ensiklopedia bebas. https://id.wikipedia.org/wiki/Jipang, Cep u, Blora. Diunduh: 15-03-2017 09.50 UTC.

Cepu, Blora - Wikipedia bahasa Indonesia, ensiklopedia bebas. https://id.wikipedia.org/wiki/Cepu, Blora . Diunduh: 15-03-2017 10.07 UTC.

Undang-undang No. 12 Tahun 2008 tentang Pemerintahan Daerah. http://www.sanitasi.net/undang-undangno-12-tahun-2008-tentang-pemerintahandaerah.html. Diunduh: 30-08-2017 13.05 UTC. 
